\title{
T-wave/QRS complex amplitude correlations with myocardial edema in patients with takotsubo syndrome
}

\author{
John E. Madias ${ }^{1,2}$
}

Published online: 19 May 2015

(C) Springer Science+Business Media New York 2015

To the Editor,

I enjoyed reading the review by Dastidar et al. [1] published online ahead of print on April 21, 2015, in the Journal, about the contributions of cardiac magnetic resonance imaging (cMRI) in the diagnosis of Takotsubo syndrome (TTS) in general and its predictive role in the emergence of lethal ventricular arrhythmias in particular. The authors delve into the relationship between the electrocardiogram (ECG) T-wave inversion and QT interval prolongation [2], and cMRI-based characterization of myocardial edema (ME), and specifically its intracardiac apicobasal ME gradient [3, 4]. Indeed, repolarization times increased from the basal to the apical sites in both the epicardium and the endocardium [4] with correlation with the increasing intensity of ME from the base to the apex. While amplitude of the inverted T-waves and duration of the corrected QT interval have been correlated with ME [3, 4], another feature of the ECG attributed to ME (i.e., attenuated amplitude of the QRS complexes) [5] has not been evaluated heretofore. Accordingly, it would be contributory to our knowledge about TTS, and its relationship to $\mathrm{ME}$ and ventricular arrhythmic consequences to correlate ME and amplitude of ECG QRS complexes employed various sets of the ECG leads, as done previously [5]. Intuitively, what appears to be a promising possibility is comparison of ME gradient with change of the amplitude of the QRS complexes between the admission ECG and the

John E. Madias

madiasj@nychhc.org

1 Icahn School of Medicine at Mount Sinai, New York, NY, USA

2 Division of Cardiology, Elmhurst Hospital Center, 79-01 Broadway, Elmhurst, NY 11373, USA subsequent ECG with the lowest amplitude of QRS complexes [5]. Indeed, comparison of the latter ECG with a previous ECG acquired prior to the admission with TTS may be the ideal comparison change to be correlated with indices of cMRI-derived ME.

Conflict of interest None.

\section{References}

1. Dastidar AG, Frontera A, Palazzuoli A, Bucciarelli-Ducci C et al (2015) TakoTsubo cardiomyopathy: unravelling the malignant consequences of a benign disease with cardiac magnetic resonance. Heart Fail Rev 21 Apr 2015. (Epub ahead of print)

2. Madias C, Fitzgibbons TP, Alsheikh-Ali AA, Bouchard JL, Kalsmith B, Garlitski AC, et al (2011) Acquired long QT syndrome from stress cardiomyopathy is associated with ventricular arrhythmias and torsades de pointes. Heart Rhythm 8(4):555-61, 30 Oct 2013. http://www.ncbi.nlm.nih.gov/pubmed/ 21146632

3. Perazzolo Marra M, Zorzi A, Corbetti F, De Lazzari M, Migliore F, Tona F, et al (2013) Apicobasal gradient of left ventricular myocardial edema underlies transient T-wave inversion and QT interval prolongation (Wellens' ECG pattern) in Tako-Tsubo cardiomyopathy. Heart Rhythm 10(1):70-7, 27 Oct 2013. http:// www.ncbi.nlm.nih.gov/pubmed/22975421

4. Furushima H, Chinushi M, Sanada A, Aizawa Y et al (2008) Ventricular repolarization gradients in a patient with takotsubo cardiomyopathy. Europace 10(9):1112-5, 30 Oct 2013. http:// www.ncbi.nlm.nih.gov/pubmed/18567569

5. Madias JE Transient attenuation of the amplitude of the QRS complexes in the diagnosis of Takotsubo syndrome. (2014) Eur Heart J Acute Cardiovasc Care 3(1):28-36, Mar 2014. doi:10. 1177/2048872613504311. (Epub 2013 Sep 18) 